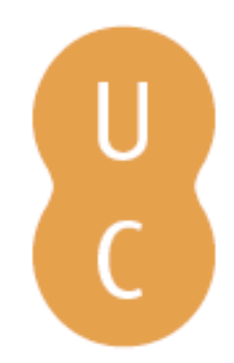

\title{
Rompalina
}

\section{Desperdício, a cultura do contraditório: reflexões para um "novo" paradigma}

\author{
Autor(es): $\quad$ Martins, Fernando \\ Publicado por: Imprensa da Universidade de Coimbra \\ URL \\ persistente: URI:http://hdl.handle.net/10316.2/30774 \\ DOI: $\quad$ DOI:http://dx.doi.org/10.14195/978-989-26-0244-8_19
}

Accessed : $\quad$ 26-Apr-2023 15:20:27

A navegação consulta e descarregamento dos títulos inseridos nas Bibliotecas Digitais UC Digitalis, UC Pombalina e UC Impactum, pressupõem a aceitação plena e sem reservas dos Termos e Condições de Uso destas Bibliotecas Digitais, disponíveis em https://digitalis.uc.pt/pt-pt/termos.

Conforme exposto nos referidos Termos e Condições de Uso, o descarregamento de títulos de acesso restrito requer uma licença válida de autorização devendo o utilizador aceder ao(s) documento(s) a partir de um endereço de IP da instituição detentora da supramencionada licença.

Ao utilizador é apenas permitido o descarregamento para uso pessoal, pelo que o emprego do(s) título(s) descarregado(s) para outro fim, designadamente comercial, carece de autorização do respetivo autor ou editor da obra.

Na medida em que todas as obras da UC Digitalis se encontram protegidas pelo Código do Direito de Autor e Direitos Conexos e demais legislação aplicável, toda a cópia, parcial ou total, deste documento, nos casos em que é legalmente admitida, deverá conter ou fazer-se acompanhar por este aviso.

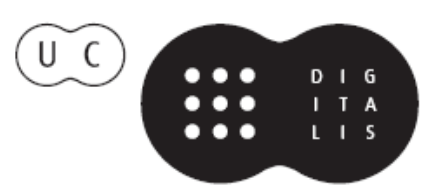




\section{TRUNFOS DE UMA}

\section{EOGRAFIA ACIVA}

\section{DESENVOLVIMENTO LOCAL,}

AMBIENTE,

ORDENAMENTO

E TECNOLOGIA

Norberto Santos

Lúcio Cunha

COORDENAÇÃO 
Fernando Martins

eGeo - Centro de Estudos de Geografia e Planeamento Regional-FCSH - UNL

\section{DESPERDÍCIO, A CULTURA DO CONTRADITÓRIO. REFLEXÓES PARA UM “NOVO” PARADIGMA}

\section{INTRODUÇÃO}

Em Portugal, à semelhança do que tem ocorrido nos países mais desenvolvidos, as preocupaçóes com os problemas ambientais, têm vindo a assumir uma importância crescente. Um longo caminho foi já percorrido nas últimas três décadas, mas muito há ainda a fazer nesta matéria. Actualmente, há mais informação disponível, mais curiosidade e interesse pelo tema, comportamentos mais adequados e práticas quotidianas mais responsáveis.

O principal propósito desta comunicação é o de chamar a atenção para o que designámos por "cultura do contraditório" (que adiante explicaremos) aplicada à questão do desperdício e, simultaneamente, apresentar algumas reflexóes que, do nosso ponto de vista, poderão contribuir para uma visão mais integrada e responsável de todos (cidadãos, empresas, governos, etc.), e, portanto, para uma melhor protecção e preservação do ambiente. Propomos uma visão alternativa à existente, onde todos participam de forma mais responsável. Actualmente, a participação dos cidadáos é sobretudo uma participação no fim do ciclo, ou seja, de forma a minorar problemas que poderiam, pelo menos em parte, ser evitados a montante. As diferenças na perspectiva de abordagem dos problemas mas, principalmente, as mudanças significativas nas formas de actuar contra o desperdício, justificam que falemos de um "novo" paradigma". E não é decerto uma utopia...

\section{DESPERDÍCIO VERSUS RESÍDUOS}

Esta reflexão incide principalmente sobre o comportamento dos consumidores enquanto geradores de resíduos, principalmente de resíduos sólidos resultantes de embalagens e de sobras de material não utilizado que deixam de ter utilidade para o seu proprietário. $\mathrm{O}$ Decreto-Lei $\mathrm{n}^{\circ} 178 / 2006$, de 5 de Setembro, define-os como "quaisquer substâncias ou objectos de que o detentor se desfaz ou tem intenção ou obrigação de se desfazer, ... ”. Aqui optámos, propositadamente, por preterir esta designação em favor da de desperdício, termo mais abrangente e, do nosso ponto de vista, mais adequado ao contexto em causa. Efectivamente, pretende-se incluir aqui não apenas os resíduos propriamente ditos mas também todo o conjunto de substâncias, independentemente da sua natureza (papel, cartão, 
plástico, ...), que mais do que resíduos constituem desperdícios desnecessários e evitáveis; é o caso, por exemplo, das multi-embalagens ou das embalagens desadequadas ao acondicionamento dos respectivos produtos.

Produtores, transportadores, distribuidores, agentes de marketing e publicidade, vendedores e consumidores, contribuem para a produção de desperdícios, embora em graus e escalas diferentes. Todos têm responsabilidade; e quem legisla também pois cabe-lhe a responsabilidade de o permitir de forma muitas vezes indiscriminada, sem controlo nem penalizaçóes adequadas.

\section{O PORQUÊ}

A reflexão que apresentamos justifica-se por quatro razóes principais. A primeira é a actualidade do tema. Há cerca de dois meses decorreu em Lisboa o Congresso Mundial de Resíduos (12-15 Outubro 2009), subordinado ao tema "Turning Waste Info Ideas transformar residuos em ideias". Oito centenas de especialistas europeus e mundiais bem como representantes de organizaçóes internacionais, com especial importância neste sector, como é o caso do Banco Mundial, do Banco Europeu do Investimento e do Programa Ambiental das Naçóes Unidas, debateram temas relacionados com a gestão, tratamento e valorização de resíduos.

A segunda razão é a sua estreita relação com grandes problemas ambientais que afectam o planeta (e nos preocupam a todos), nomeadamente com os relacionados com o aquecimento global e as alteraçóes climáticas, com a perda de biodiversidade ou com a preservação de habitats e ecossistemas ameaçados de extinção. Tanto em Portugal como a nível europeu e mundial, a preocupação com os resíduos e o desperdício em geral está na ordem do dia e, entre nós, têm-se multiplicado as acçóes de sensibilização e informação com vista ao envolvimento e participação de todos (cidadãos, empresas, governos, ....).

Há mais de uma década estas matérias fazem parte dos curricula das escolas; a comunicação social em geral tem contribuído para que o público esteja informado e seja ambientalmente mais responsável e, simultaneamente, se denunciem os "crimes ambientais"; os projectos de educação e investigação, em escolas e universidades, têm-se multiplicado, as empresas estão cada vez mais receptivas à inovação e à adaptação; ambientalistas e vários sectores da sociedade estáo alerta; alguns exemplos de boas práticas ambientais encorajam- nos...

A terceira razão relaciona-se com a produção de resíduos em Portugal que não pára de aumentar ${ }^{2}$, produzindo cada português, em média, cerca de $1,3 \mathrm{~kg} / \mathrm{dia}$, o equivalente a $300 \mathrm{~kg} / \mathrm{ano}$; e até 2020 este montante deverá sofrer um acréscimo de $20 \%$, segundo as previsóes. Por outras palavras, significa que a recuperação de resíduos de embalagens que tem crescido nos últimos anos (+26\% entre 2006 e $2007^{3}$ e $+7 \%$ entre 2007 e 2008) está longe de ser considerada suficiente. Para cumprir as metas estabelecidas com a UE, Portugal

\footnotetext{
${ }^{1} \mathrm{O}$ congresso foi organizado pela Associação Internacional de Resíduos Sólidos (ISWA) e pela Associação Portuguesa de Engenharia Sanitária e Ambiental (APESD) e decorreu no Centro Cultural de Belém.

${ }^{2}$ A recolha de embalagens cobre já mais de $90 \%$ do território e da população portuguesa, de acordo com João Letras, director do Departamento de Gestão de Resíduos da Sociedade Ponto Verde (SPV).

${ }^{3}$ De acordo com a Sociedade Ponto Verde.
} 
terá ainda de aumentar a retoma de embalagens colocadas no mercado de $43 \%$ registados em $2008^{4}$ para $55 \%$ em $2011^{5}$.

Por último, porque nos parece chegado o momento de dar um novo "salto", tendo por base o último elo da cadeia, os consumidores, que de uma forma muito genérica poderiamos caracterizar como sendo cidadãos pouco informados, pouco participativos, e ambientalmente irresponsáveis. Alterar esta situaçáo poderia evitar o aparecimento de uma parte significativa de resíduos desnecessários com os consequentes ganhos ambientais. Em vez da política dos "3R" (reduzir, reutilizar, reciclar) preferiríamos a política dos "E3R" (evitar, reduzir, reutilizar, reciclar), com particular destaque para o termo evitar, que do nosso ponto de vista deveria vir logo em primeiro lugar.

\section{RESPONSABILIDADE}

Ainda que de uma forma mais ou menos inconsciente, o cidadão comum é levado a pensar que, em matéria de resíduos, a sua principal contribuição está na sua separação e deposição nos locais apropriados. Efectivamente, é isto que lhe tem sido pedido e ele tem-no feito de forma cada vez mais generalizada, tanto no local de trabalho como no âmbito familiar.

A comunicação social, principalmente a televisão, tem tido uma função pedagógicodidáctica muito importante junto da sociedade portuguesa, procurando que públicos de todas as idades e estratos sociais percebam a importância de boas práticas ambientais. Felizmente, hoje, são poucos os que questionam as boas práticas reconhecendo que é, com o esforço e a participaçáo de cada cidadáo, individualmente, que todos podemos contribuir para minorar os problemas ambientais à escala local, regional e até global, parte dos quais resultantes de situaçóes de desperdício.

A escola, através da educação de crianças e jovens tem tido um papel muito activo, e estes últimos têm sido também grandes responsáveis pelas mudanças de práticas e comportamentos de pais e familiares. Seguir boas práticas ambientais, por compreensão e reconhecimento das mais valias que lhe estáo associadas ou simplesmente por imitaçáo, como tantas vezes acontece, têm permitido a recuperação de muitas toneladas de desperdícios/resíduos que, de outro modo, não teriam o destino desejável (leia-se reutilizadas, recicladas, ...).

Um longo caminho foi já percorrido mas muito mais teremos ainda que percorrer. Em pouco mais de três décadas (pós 25 de Abril), mas sobretudo nas últimas duas, conseguimos melhorias ambientais assinaláveis, só possíveis porque contaram com o envolvimento e a participação de todos (governos, empresas, cidadãos...). Mas estamos ainda muito longe de atingir a situação desejável. O que designámos por "cultura do contraditório" no título desta pequena reflexão prende-se precisamente com o longo caminho que ainda teremos de percorrer, para alcançar o que parece inalcançável. A visão que melhor pode caracterizar a

\footnotetext{
${ }^{4}$ As taxas absolutas de reciclagem, ou seja, "tendo em conta as quantidades colocadas no mercado e as que foram encaminhadas para reciclagem", registam valores de $78 \%$ nos resíduos de papel/cartão, $65 \%$ no metal; $52 \%$ no vidro, 19\% no plástico e $11 \%$ nos resíduos de madeira. (Informaçáo disponível em: http://www.ambienteonline.pt/ /noticias/detalhes.php?id=8459).

${ }^{5}$ Só nos primeiros seis meses de 2009 já foram recicladas 285013 toneladas.
} 
situação já não é a de uma encruzilhada onde é preciso escolher, de entre vários, o melhor caminho. Esse foi o desafio que enfrentámos nas décadas de 80 e 90 do século XX. Actualmente, conhecemos o rumo e sabemos qual o caminho que devemos trilhar. O problema é que esse caminho que sempre foi sinuoso, estreito e difícil, apresenta obstáculos e dificuldades acrescidas. Vejamos alguns desses obstáculos.

O primeiro é a propensão para um certo tipo de consumo que, à semelhança do que acontece em muitos outros países, está cada vez mais enraizado transversalmente na sociedade portuguesa. Como refere Daniel Goleman (2006: 10) “...vivemos o nosso quotidiano imersos num mar de coisas que compramos, usamos e deitamos fora, desperdiçamos ou guardamos...". Compramos o que precisamos, o que dizem que nos faz falta, o que está em saldo ou a preço baixo, o que está na moda, o que achamos adequado à nossa posiçáo social ou o que invejamos nos outros, sejam eles nossos vizinhos ou figuras públicas da televisão, do cinema, da moda ou das revistas em geral. Pode-nos servir para pouco, podemos nem sequer tirar partido das mais valias desses produtos, mas vale sempre a pena por maior que possa ter sido o sacrifício em adquiri-lo. E damos nas vistas, e mostramo-lo; e levamos a que outros façam o mesmo que nós fizemos: compras. E há aqueles que dizem ser imunes a tudo isto. Mas, mais cedo ou mais tarde acabam também por ceder e ei-los como os outros (a outra escala é certo!) a cometer os mesmos "erros" que antes criticaram.

Cesare Guerreschi, presidente da Sociedade Italiana de Intervençôes sobre as Patologias Compulsivas, e reputado psicólogo italiano, explica de modo notável esta dependência enquanto "fenómeno extremamente complexo, que engloba inúmeros aspectos da esfera individual, tantos que se torna impossivel dar uma definição precisa e aceite por toda a comunidade científica". Dependência, co-dependência, co-morbilidade, novas formas de dependência, etc., são conceitos associados à temática da "sociedade de consumo" que aqui náo iremos desenvolver, mas que ajudam a explicar o que o autor designou por "novas dependências"'.

O segundo obstáculo a melhores práticas ambientais é o tipo de vida a que nos habituámos. O nosso quotidiano é, actualmente, marcado não só pelo consumo desenfreado mas também por estilos de vida muito diferentes dos que dominavam há apenas duas ou três décadas. Outros estilos, outros modos de vida, outros ritmos, outras dependências. Bens pouco conhecidos há vinte ou trinta anos, como o telemóvel, por exemplo, estão agora generalizados por todas as idades e estratos sociais; e os exemplos são inúmeros, quer estejamos a referir-nos a equipamentos, a vestuário, a mobiliário, a bens alimentares, ou a quaisquer outros. E a dependência é tal, que parece que a vida actual já não faz sentido sem a sua presença. Às vezes parece mesmo que a nossa sobrevivência depende da sua existência e que eles sempre estiveram ao nosso dispor. Mas tão inseparáveis nos achamos deles que, na primeira oportunidade que nos surge, os substituímos por outros, supostamente muito mais importantes, ainda que essa importância se possa medir apenas pela cor, pela dimensão ou por uma ou outra funcionalidade que, no futuro, poucas vezes iremos utilizar. E passamos o dia-a-dia desperdiçando tempo, dinheiro, energia, ...

O encurtamento do tempo de vida útil dos produtos, é outros dos grandes obstáculos. Inúmeros bens, dos frigoríficos aos telemóveis, dos automóveis aos computadores, para

\footnotetext{
${ }^{6}$ Guerreschi C. 2005, Le nuove dipendenze, Edizioni San Paolo, Miláo. Obra traduzida para português por Paulinas Editora, em 2009, com o título As novas dependências. Internet, trabalho, sexo, telemóvel e shopping compulsivo.
} 
referir apenas estes, têm vindo a registar um decréscimo generalizado do tempo de utilização que deles fazemos, do designado tempo de vida útil, ao fim do qual ninguém os quer. Variadas razóes, há muito identificadas, têm contribuído para isso; a menor durabilidade dos produtos, a sua rápida desactualização, o aparecimento de alternativas mais adequadas ou desejáveis, o preço relativo, a nossa maior capacidade económica e a maior propensão para o consumo, muito facilitado pelo crédito rápido, ou as "agressivas" campanhas de publicidade e marketing, a que é difícil resistir, aparecem em lugar de destaque. E é certo que os momentos de grave crise nacional e internacional, como o que presentemente se verifica, refreiam o consumo; porém, constituem períodos mais ou menos transitórios que apenas retardam o inevitável comportamento consumista, desejável para o regular funcionamento da economia.

Entre variadíssimos outros aspectos que poderíamos referir, estes parecem-nos suficientes para explicar a nossa principal linha de raciocínio. Ao mesmo tempo que crescem as nossas preocupaçóes ambientais e começamos a agir como cidadáos mais conscientes e ambientalmente mais responsáveis, menos nos damos conta de que o nosso no dia-a-dia, contradiz o que muitas vezes já julgamos ser: ambientalmente informados e com práticas diárias responsáveis. De facto, podemos até estar informados, preocuparmo-nos com a separação dos lixos, andarmos de transporte público e até contribuir para que outros também tenham boas práticas ambientais; mas, ainda assim, estamos longe de atingir o nível desejável.

\section{“CUltura Do CONTRAditório"}

A vida quotidiana dos cidadãos portugueses pauta-se, pelo menos em matéria de ambiente, por um conjunto de incoerências, não apenas no discurso mas, principalmente, nas lógicas de actuação e nas práticas correntes. Nuns casos os cidadãos ignoram as boas práticas ainda que às vezes as conheçam; noutros o discurso e a prática contradizem-se. São estas incongruências que designámos por "cultura do contraditório".

Diariamente, os cidadãos são "bombardeados" com informaçóes sobre como podem ajudar o planeta. E dizem-lhes que devem deslocar-se em transportes públicos em vez de utilizarem o automóvel; que devem separar os lixos; que devem substituir as lâmpadas por outras mais economizadoras de energia; que devem poupar água; ... enfim, que devem mudar de hábitos. E os cidadãos lá vão, pouco a pouco cumprindo o que lhes é pedido ou exigido, muitas vezes convictos que dessa forma se tornam "eco-cidadãos", ainda que desconheçam este termo e o seu significado.

A questão dos desperdícios, e particularmente a dos resíduos, enferma ainda de um outro problema: o de facilmente nos desfazermos deles, no caixote do lixo ou no ecoponto. E assim deixam de pertencer a quem os gerou e de haver responsabilidade individual sobre o destino final a dar-lhes. O principal contributo dos cidadáos tem sido através do pagamento de uma taxa de produção de resíduos que, em vez de estar relacionada com o peso/volume dos resíduos produzidos, é proporcional ao consumo de água ${ }^{7}$. E motivar

\footnotetext{
${ }^{7}$ Actualmente, em alguns concelhos do norte do País está já a ser testada uma forma diferente e mais justa de taxar a produção de resíduos, de acordo com o seu peso, através de dispositivos de medição automática do peso dos resíduos colocados nos contentores do lixo.
} 
os cidadãos a colocarem os resíduos no local adequado foi uma tarefa morosa e difícil, conseguida apenas em parte. Mas é preciso fazer muito mais, e isso depende da colaboração de todos, principalmente dos consumidores.

\section{A EMERGÊNCIA DE UM “NOVO” PARADIGMA}

Parece-nos chegado o momento de tentar mudar a filosofia, a estratégia e a forma de participação de cada cidadão individualmente. Não será decerto nas próximas geraçóes, mas entendemos poder e dever ser prioritário alcançar esses objectivos. Como? Por um lado dando-lhes mais informaçáo, pois ela é a base das melhores escolhas; depois, tornando-os agentes activos e responsáveis, capazes de avaliar por si só as melhores opçóes em matéria de protecção ambiental, nomeadamente no que se refere à compra dos "melhores" produtos. Escolhendo os menos lesivos para o ambiente e os menos geradores de resíduos e desperdícios, preterindo por exemplo os que têm várias embalagens ou embalagens desadequadas. Em síntese, tornando-os cidadãos informados que pensem antes de agir e que ajam por princípios e convicçôes correctas.

Os consumidores estão no fim do ciclo mas o mercado depende essencialmente deles. Isolados não têm voz mas, uma vez unidos e sincronizados, podem exercer grande influência sobre as empresas e o mercado em geral. Nunca as geraçóes estiveram táo ligadas entre si como agora, nem nunca as notícias foram difundidas de modo tão rápido. Simples mensagens através de telemóvel ou da rede de internet permitem hoje reunir ou influenciar milhares de pessoas e responder às empresas de uma forma tão "poderosa" que podem abalar a reputaçáo de uma marca ou produto. E são também o modo cada vez mais usual de partilhar conhecimento, o factor-chave dos "eco-cidadãos" do futuro.

Por outro lado, facilitando o acesso dos cidadãos à informação, ou seja, simplificando informação útil sobre a generalidade dos produtos existentes no mercado (origem, constituição, processos de produção, destino final, implicaçōes ambientais, etc.) e tornando-a acessível e entendível pelo público.

A emergência de um "novo" paradigma começará quando formos capazes de agir conscientemente e não por impulso, quando verdadeiramente percebermos as consequências dos nossos actos mas, principalmente, quando tivermos consciência da sua gravidade. E na base de tudo isso está a formação e a informação a que cada um de nós tem acesso, cujos indicadores nacionais (níveis de escolaridade, iliteracia, participação pública, etc.), revelam ainda atrasos significativos relativamente aos principais países da Uniâo Europeia onde nos integramos.

Como escreveu Daniel Goleman (2009: 14) “imaginem o que poderia acontecer se tivéssemos acesso ao conhecimento que agora se encontra confinado aos especialistas, como os ecologistas industriais: ensinado às crianças nas escolas, facilmente acessivel na Internet, condensado nas avaliaçóes das coisas que compramos e fazemos, e resumido quando estivéssemos prestes a fazer uma compra". Ficaríamos a conhecer o verdadeiro impacto das nossas opçóes e poderíamos decidir com total transparência.

Para podermos dar os primeiros passos neste sentido sugerimos duas medidas concretas; uma relacionada com a disponibilização de informação mais criteriosa aos consumidores permitindo-lhes tomar decisóes ambientalmente mais adequadas, a outra com vista a uma actuação mais a montante, visando penalizar ou interditar más práticas ambientais. 
A primeira medida baseia-se no princípio dos ecorrótulos e permitiria ao consumidor saber quais os produtos mais amigos do ambiente. Não o ecorrótulo já existente que identifica um produto como tendo sido produzido de acordo com as normas ambientais mas uma ficha contendo informaçóes precisas sobre esse produto. Não apenas no que se refere à sua constituição e perigosidade mas uma verdadeira base de dados sobre o modo como foram obtidos os seus constituintes, como foi produzido ou fabricado, quais as consequências ambientais decorrentes da sua utilizaçáo e do destino final a dar-lhe quando deixar de ter utilidade. Tal transparência permitiria boas escolhas mas seria inviável pela morosidade da leitura, isto supondo que seria possível entender o significado de termos complexos que necessariamente teriam de constar. Para ultrapassar este problema sugere-se a criação de um sistema simples, semelhante ao que classifica os electrodomésticos do ponto de vista do seu desempenho energético. Uma classificação indexada a uma escala gradativa que permitisse comparar produtos semelhantes. Complementarmente, uma base de dados na internet permitiria que em qualquer momento fosse possível uma consulta prévia a informação mais pormenorizada, que decerto ajudaria a tomar melhores decisóes. Nos próprios locais de venda também deveria ser possível aceder a essa informação através do código de barras do produto.

A segunda medida relaciona-se com o mercado da publicidade e do marketing, nomeadamente com a necessidade de regular a comunicação entre vendedores e consumidores. A publicidade em papel constitui actualmente um elemento de forte impacto ambiental decorrente não só da produção de resíduos mas também do facto desses resíduos estarem frequentemente impregnados de enormes quantidades de produtos químicos (tintas) que tornam difícil o seu reaproveitamento. E seria táo fácil evitá-los.

\section{SÍNTESE FINAL}

As tendências actuais parecem apontar para o despertar de uma sociedade mais atenta, mais interessada, mais preocupada e mais ávida de informação. Mas é preciso mudar. Antes de mais, mudar a forma de pensar dos cidadáos, ou seja, fazendo-os pensar à priori e náo à posteriori de modo a evitar o que puder ser evitado em matéria de desperdício; em segundo lugar, mudar a forma de agir, procurando que eles o façam de modo consciente e não por impulso, como tantas vezes acontece nas situaçóes de compra; e, na medida do possível, mudar também a lógica de funcionamento da economia e da sociedade, valorizando as boas práticas ambientais e desincentivando / penalizando as más. Um "novo" paradigma sustenta-se necessariamente nestes e noutros princípios. Desperdício haverá sempre; o importante é que sejamos capazes de o reduzir, evitando o que puder ser evitável. O restante, que seja devidamente tratado e encaminhado. A educação, a investigação, a inovação e o desenvolvimento tecnológico ajudar-nos-ão a consegui-lo de modo cada vez mais adequado.

\section{REFERÊNCIAS BIBLIOGRÁFICAS}

Al Gore 2009, A nossa escolha. Um plano para resolver a crise climática, Esfera do Caos Editores (tradução portuguesa). 
Aragão, M. 1997, O princípio do poluidor pagador, pedra angular da política comunitária do ambiente. Boletim da Faculdade de Direito Studia Ivridica 23, Universidade de Coimbra, Coimbra Editora, Coimbra.

Ferreira, J. V. 2004, Análise do ciclo de vida dos produtos, Instituto Politécnico de Viseu. Disponível em WWW:URL:http://www.estv.ipv.pt

Goleman, D. 2009, Eco-inteligências. Como o consumismo mudou o mundo. Temas e Debates, Rio de Mouro.

Guerreschi, C. 2009, As Novas dependências. Internet, trabalho, sexo, telemóvel e shopping compulsivo, Paulinas Editora, Prior Velho. (Tradução do original italiano de 2005). 